\title{
PERAN EMOTIONAL BONDING DALAM MEMEDIASI HUBUNGAN CITRA DESTINASI WISATA DAN TINGKAT KEPUASAN TERHADAP LOYALITAS WISATAWAN YANG BERKUNJUNG KE WISATA PARALAYANG TOROK AIK BELEQ
}

\section{Wiji Rosiana ${ }^{1}$, Hermanto ${ }^{2}$, Akhmad Saufi ${ }^{3}$}

${ }^{1}$ Program Studi Magister Management, Fakultas Ekonomi dan Bisnis, Unram E-mail: rseriant@gmail.com

2 Fakultas Ekonomi dan Bisnis, Universitas Mataram E-mail: hermanto2307@gmail.com

3 Fakultas Ekonomi dan Bisnis, Universitas Mataram . E-mail: akh.saufi72@gmail.com

\begin{tabular}{|c|c|}
\hline ARTICLE INFO & ABSTRACT \\
\hline 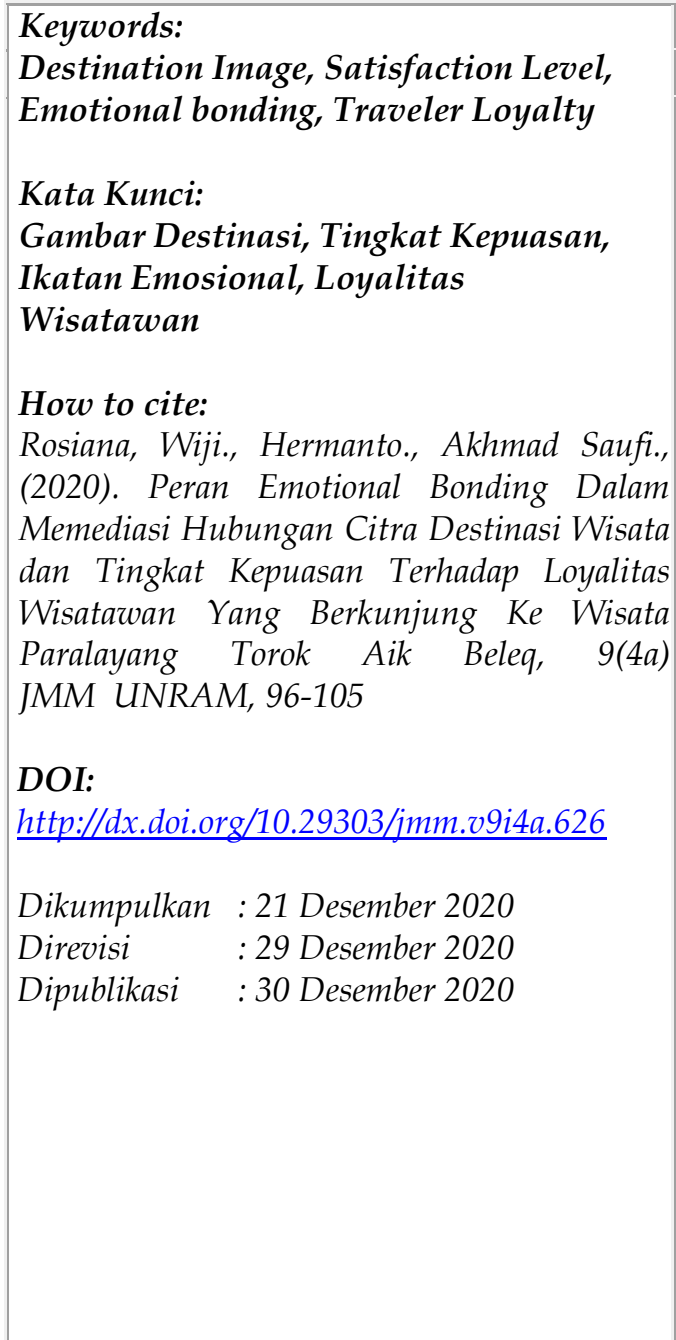 & $\begin{array}{l}\text { This study aims to provide an understanding of the role } \\
\text { of emotional bonding in mediating the influence of } \\
\text { destination image and satisfaction level on tourist loyalty. } \\
\text { Data collection is done by quizzing respondents, namely } \\
\text { pilots registered with FASI NTB using quantitative } \\
\text { methods. The results of this study prove that the image of } \\
\text { the destination and the level of satisfaction affect the } \\
\text { loyalty of tourists, the image of the destination and the } \\
\text { level of satisfaction affects emotional bonding and } \\
\text { emotional bonding mediating the influence of the image of } \\
\text { the destination and the level of satisfaction to the loyalty } \\
\text { of tourists. The Government of West Nusa Tenggara and } \\
\text { the organization FASI NTB and the community around } \\
\text { paragliding tourism Torok Aik Beleq are advised to hold } \\
\text { continuous sports tourism every year to attract tourists } \\
\text { to visit the destination. } \\
\text { Penelitian ini bertujuan untuk memberikan } \\
\text { pemahaman tentang peran emotional bonding dalam } \\
\text { memediasi pengaruh citra destinasi dan tingkat kepuasan } \\
\text { terhadap loyalitas wisatawan. Pengumpulan data } \\
\text { dilakukan dengan memeberikan kuisioner terhadap } \\
\text { responden yaitu pilot yang terdaftar di FASI NTB } \\
\text { dengan menggunakan metode kuantitatif. Hasil } \\
\text { penelitian ini membuktikan bahwa citra destinasi dan } \\
\text { tingkat kepuasan berpengaruh terhadap loyalitas } \\
\text { wisatawan, citra destinasi dan tingkat kepuasan } \\
\text { berpengaruh terhadap emotional bonding dan emotional } \\
\text { bonding memediasi pengaruh citra destinasi dan tingkat } \\
\text { kepuasan terhadap loyalitas wisatawan. Pemerintah } \\
\text { Nusa Tenggara Barat dan organisasi FASI NTB serta } \\
\text { masyarakat sekitar wisata paralayang Torok Aik Beleq } \\
\text { disarankan untuk menyelenggarakan pariwisata olahraga }\end{array}$ \\
\hline
\end{tabular}




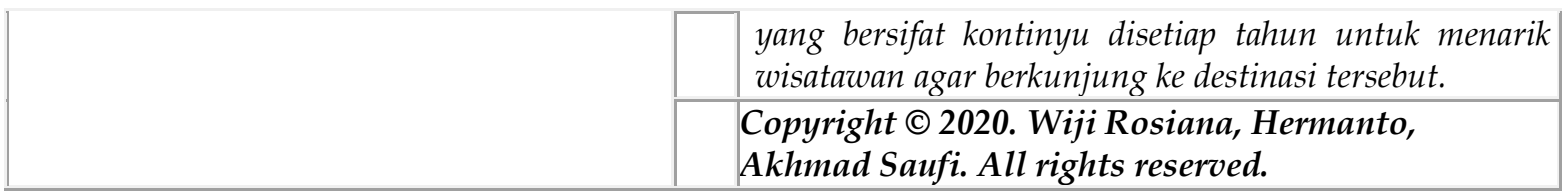

\section{PENDAHULUAN}

Pariwisata olahraga merupakan perpaduan antara olahraga dan wisata, yang sekarang sudah berkembang dan terus mengalami peningkatan wisatawan. Menurut Ismayanti (2010), wisata olahraga memadukan kegiatan olahraga dengan kegiatan wisata. Kegiatan dalam wisata ini dapat berupa kegiatan olahraga aktif yang mengharuskan wisatawan melakukan gerak olah tubuh secara langsung. Kegiatan lainnya dapat berupa kegiatan olahraga pasif. Dimana wisatawan tidak melakukan gerak olah tubuh, melainkan hanya menjadi penikmat dan pecinta olahraga saja. Dewasa ini pariwisata olahraga sudah menjadi sebuah unsur yang penting dalam dunia pariwisata karena telah menjadi bisnis pariwisata yang sangat kompetitif.

Lita dan Ma'ruf (2015) mengatakan bahwa acara olahraga berdampak pada perkembangan sektor pariwisata, dimana saat pertandingan Olimpiade di Beijing berdampak pada kedatangan wisatawan asing yang menigkat 8-9 persen pertahun setelah event itu berlangsung. Hal tersebut menunjukan bahwa event tersebut dapat mendorong kegiatan kunjungan dan juga memberikan efek multi-sektor pada tujuan wisata. Di Provinsi Nusa Tenggara Barat sendiri di tahun 2019 lalu telah diadakan event Paralayang TROI Seri 3 Mandalika yang diselenggarakan di Bukit Sombeng Pantai Torok Aik Beleq Desa Montong Ajan Kecamatan Praya Barat Daya Kabupaten Lombok Tengah, yang diikuti lebih dari 200 Atlet yang terdiri 94 Atlet Nasional, 100 Atlet dari NTB dan dua Atlet dari India.

Kepuasan wisatawan dianggap sebagai faktor utama dalam menentukan sektor pariwisata dan wisatawan yang dapat membuat mereka kembali mengunjungi tujuan wisata atau menonton ulang event paralayang di pantai Torok Aik Beleq. Chen dan Tsai (2007) berpendapat bahwa kepuasan wisatawan adalah konsep sentral dalam pariwisata. Semakin baik citra destinasi suatu tempat wisata maka melekat dalam ingatan wisatawan sehingga menimbulkan loyalitas kepada tempat wisata tersebut. Emotional Bonding dimana konsumen dapat terpengaruh oleh sebuah merek yang dimiliki daya tarik tersendiri sehingga konsumen dapat diidentifikasikan dalam sebuah merek atau citra, karena sebuah merek ataupun citra mencerminkan karakteristik konsumen tersebut. Ikatan yang tercipta dari sebuah merek maupun citra ialah ketika konsumen merasakan ikatan yang kuat dengan konsumen lain yang menggunakan produk atau jasa yang sama (Zikmund dalam Soegoto, 2003).

Adanya perbedaan hasil penelitian mengenai pengaruh citra destinasi dan tingkat kepuasan terhadap loyalitas wisatawan dan belum adanya penelitian yang mengaitkan emotional bonding terhadap loyalitas wisatawan sehingga upaya menggabungkan antara citra destinasi, tingkat kepuasan, emotional bonding dan loyalitas wisatawan menjadi menarik untuk diteliti. Penelitian ini bertujuan untuk memberikan pemahaman tentang faktor-faktor yang mempengaruhi loyalitas wisatawan yang berkunjung ke wisata olahraga paralayang Torok Aik Beleq. 


\section{KAJIAN PUSTAKA}

\subsection{Loyalitas Wisatawan}

Loyalitas wisatawan adalah tindakan kunjungan ulang dan merekomendasikan obyek wisata kepada pihak lain. Menurut Bramson (2005) indikator pengukurannya meliputi: keinginan untuk membeli ulang, keinginan pelanggan untuk tidak beralih pada produk lain, merasa bahwa produk tersebut sesuai dengan yang diharapkan, kemauan untuk tetap menggunakan selamanya, keinginan untuk merekomendasikan pada orang lain.

Loyalitas merupakan kesediaan pelanggan untuk senantiasa memakai produk suatu perusahaan dalam jangka waktu yang panjang, bahkan menggunakannya secara ekslusif, merekomendasikan produk-produk tersebut pada orang lain (Lovelock et al. 2010).

\subsection{Citra Destinasi}

Citra (image) pariwisata menurut Pitana dan Diarta (2009) adalah kepercayaan yang dimiliki oleh wisatawan mengenai produk atau pelayanan yang wisatawan beli atau akan beli. Citra destinasi tidak selalu terbentuk dari pengalaman atau fakta, tetapi dapat dibentuk sehingga menjadi faktor motivasi atau pendorong yang kuat untuk melakukan perjalanan wisatawan ke suatu destinasi pariwisata.

Citra destinasi dianggap mampu mempengaruhi perilaku seseorang termasuk proses pengambilan keputusan, evaluasi selama berada pada suatu destinasi wisata yang hasilnya berupa kepuasan dan dorongan untuk berperilaku ke depan yang hasilnya berupa dorongan untuk berkunjung kembali dan positif WOM (Ling et al, 2010).

\subsection{Kepuasan Wisatawan}

Prayag mengatakan (dalam Coban, 2012), kepuasan wisatawan merupakan ukuran keseluruhan dari pendapat wisatawan pada setiap kualitas destinasi.Ukuran tersebut dapat dipertimbangkan sebagai nilai mengenai kualitas hasil dari destinasi pariwisata, misalnya perlakuan dan pelayanan yang dirasakan wisatawan terhadap destinasi pariwisata, tetapi tidak hanya hasil pada akhir pengalamannya (Coban, 2012).

\subsection{Emotional Bonding}

Dalam penelitian Gaffar (2007), Ikatan emosi (Emotional bonding) adalah dimana konsumen dapat terpengaruh oleh sebuah merek yang memiliki daya tarik tersendiri sehingga konsumen dapat diidentifikasikan dalam sebuah merek, karena sebuah merek dapat mencerminkan karakteristik konsumen tersebut. Ikatan yang tercipta dari sebuah merek ialah ketika konsumen merasakan ikatan yang kuat dengan konsumen lain yang menggunakan produk atau jasa yang sama.

Menurut Morgan dan Hunt (dalam Egan, 2001), hubungan yang terjadi antara perusahaan dengan konsumen banyak ditentukan oleh kepercayaan dan komitmen. Kepercayaan berkaitan dengan emotional bonding yaitu kemampuan seseorang untuk mempercayakan perusahaan atau sebuah merekuntuk menjalankan sebuah fungsi, sehingga dapat diperkirakan bahwa kepercayaan akan mempunyai hubungan yang positif dengan minat beli ulang dan loyalitas. 


\subsection{Hubungan Antar Variabel}

Hubungan Citra Destinasi dengan Loyalitas Wisatawan

Menurut Hanif et al (2016) dalam penelitiannnya membuktikan variabel citra destinasi berpengaruh positif dan signifikan terhadap variabel loyalitas wisatawan. Penelitian Hu et al (2009) menyatakan bahwa Citra (image) perusahaan berpengaruh positif terhadap behavioral intentions atau loyalitas. Penelitian Lai dan Babin (2009) menyatakan bahwa Citra (image) perusahaan berpengaruh signifikan terhadap loyalitas pelanggan. H1: Citra Desinasi berpengaruh positif dan signifikan terhadap Loyalitas Wisatawan Hubungan Tingkat Kepuasan dengan Loyalitas Wisatawan

Menurut Putri et al (2015) dalam penelitiannya membuktikan bawa tingkat kepuasan berpengaruh positif dan signifikan terhadap loyalitas wisatawan yang berkunjung ke Candi Borobudur. Selain itu dalam penelitian Ernawati (2012) menyatakan bahwa kepuasan, kepercayaan dan harga sangat kuat mempengaruhi loyalitas wisatawan. Semakin tinggi tingkat kepuasan maka semakin tinggi pula loyalitas wisatawan untuk menggunakan layanan jasa (Wulandari, 2016). Hasil penelitian Setiawan dalam Putra (2017) membuktikan bahwa kepuasan berpengaruh positif dan signifikan terhadap loyalitas wisatawan..

H2: Tingkat Kepuasan berpengaruh positif dan signifikan terhadap Loyalitas Wisatawan Hubungan Citra Destinasi dengan Emotional Bonding

Menurut Lopes (dalam Surya, 2018) konsep citra destinasi berhubungan dengan ekpresi dari semua pengetahuan obyektif, prasangka, imajinasi dan ikatan emosional seseorang atau kelompok tentang destinasi tertentu. Citra destinasi terdiri dari hasil penilaian rasional dan memiliki ikatan emosional terhadap destinasi tersebut

Ketertarikan pada suatu tempat atau citra dari suatu destinasi menggambarkan ikatan emosional atau emotional bonding yang dimiliki seseorang terhadap suatu tempat atau destinasi (Smith dalam Lee et al, 2012).

H3: Citra Destinasi berpengaruh positif dan signifikan terhadap Emotional Bonding Hubungan Tingkat Kepuasan dengan Emotional Bonding

Menurut Kotler (2003), hubungan antara kepuasan dan loyalitas adalah saat dimana konsumen mencapai tingkat kepuasan tertinggi yang menimbulkan ikatan emosi yang kuat dan komitmen jangka panjang dengan merek perusahaan. Ikatan emosional (emotional bonding) yang kuat terhadap suatu perusahaan ditimbulkan oleh adanya pengaruh dari tingginya tingkat kepuasan dari pelanggan (Putri et al, 2015).

H4: Tingkat Kepuasan berpengaruh positif dan signifikan terhadap Emotional Bonding Hubungan Citra Destinasi dan Tingkat Kepuasan terhadap Loyalitas Wisatawan melalui Emotional Bonding

Barnes (2003) dalam penelitiannya mengatakan bahwa pelanggan yang memiliki loyalitas sejati merasakan adanya ikatan emosional yang membuat pelanggan menjadi loyal dan mendorong mereka untuk terus berbisnis dengan organisasi tersebut. Dengan demikian loyalitas konsumen merupakan bukti dari ikatan emosional yang mentransformasikan perilaku pembelian ulang barang atau penggunaan jasa dan adanya kecenderungan niat untuk merekomendasikan kepada orang lain, karena adanya kecintaan atau kedekatan konsumen pada perusahaan penyedia jasa atau organisasi lain (Ernawati, 2011).

H5: Emotional Bonding memediasi pengaruh Citra Destinasi dan Tingkat Kepuasan Terhadap Loyalitas Wisatawan. 


\section{METODE PENELITIAN}

\subsection{Metode Penelitian}

Penelitian ini menggunakan metode kuantitatif. Populasi dalam penelitian ini adalah seluruh pilot paralayang yang terdaftar di FASI Provinsi Nusa Tenggara Barat yang melakukan kegiatan wisata paralayang di bukit torok aik beleq. Teknik pengumpulan sampel dalam penelitian ini adalah sensus. jumlah sampel yang akan diteliti adalah sebanyak 101 orang sebagai sampel. Teknik analisis data pada penelitian ini adalah analisis jalur (path analysis). Data dianalisis menggunakan SPSS (Statistic Package for the Social Science) versi 22.

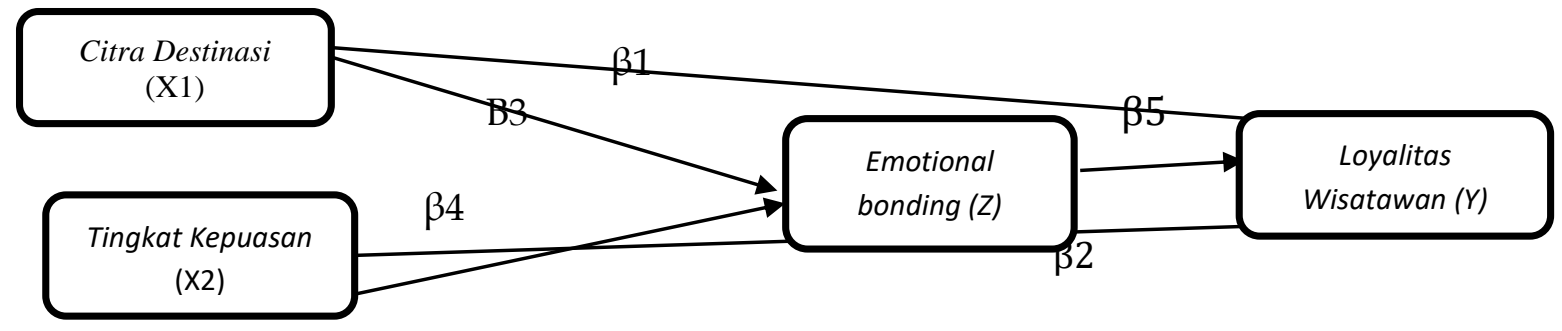

Gambar 1. Analisis Jalur

\subsection{Instrumen Penelitian}

Penelitian ini menggunakan instrumen penelitian berupa kuesioner yang terdiri dari 28 pertanyaan. Pertanyaan-pertanyaan penelitian tersebut menerangkan 4 variabel yang diteliti dalam penelitian ini.

Tabel 2. Hasil Uji Validitas dan Reliabilitas

\begin{tabular}{|c|c|c|c|}
\hline Variabel & Pertanyaan & Korelasi Pearson $>0,30$ & Ket \\
\hline \multirow{9}{*}{ Citra Destinasi Wisata (x1) } & $X 1.1$ & 0,630 & Valid \\
\hline & $X 1.2$ & 0,588 & Valid \\
\hline & $X 1.3$ & 0,538 & Valid \\
\hline & $X 1.4$ & 0,574 & Valid \\
\hline & $X 1.5$ & 0,588 & Valid \\
\hline & $X 1.6$ & 0,588 & Valid \\
\hline & $X 1.7$ & 0,584 & Valid \\
\hline & X1.8 & 0,582 & Valid \\
\hline & $X 1.9$ & 0,545 & Valid \\
\hline \multicolumn{4}{|c|}{ Cronbach's Alpha: 0,855>0,70 (Reliabel) } \\
\hline \multirow{7}{*}{ Tingkat Kepuasan (x2) } & $\mathrm{X} 2.1$ & 0,547 & Valid \\
\hline & $\mathrm{X} 2.2$ & 0,580 & Valid \\
\hline & $\mathrm{X} 2.3$ & 0,545 & Valid \\
\hline & $\mathrm{X} 2.4$ & 0,591 & Valid \\
\hline & $\mathrm{X} 2.5$ & 0,617 & Valid \\
\hline & $\mathrm{X} 2.6$ & 0,569 & Valid \\
\hline & $\mathrm{X} 2.7$ & 0,587 & Valid \\
\hline \multicolumn{4}{|c|}{ Cronbach's Alpha: 0,828 > 0,70 (Reliabel) } \\
\hline \multirow{7}{*}{ Emotional Bonding (Z) } & Z.1 & 0,551 & Valid \\
\hline & $\mathrm{Z} .2$ & 0,530 & Valid \\
\hline & Z.3 & 0,578 & Valid \\
\hline & Z.4 & 0,485 & Valid \\
\hline & Z.5 & 0,511 & Valid \\
\hline & Z.6 & 0,539 & Valid \\
\hline & $\mathrm{Z} .7$ & 0,486 & Valid \\
\hline \multicolumn{4}{|c|}{ Cronbach's Alpha: 0,793>0,70 (Reliabel) } \\
\hline \multirow{5}{*}{ Loyalitas Wisatawan (y) } & Y.1 & 0,718 & Valid \\
\hline & Y.2 & 0,788 & Valid \\
\hline & Y.3 & 0,688 & Valid \\
\hline & Y.4 & 0,774 & Valid \\
\hline & Y.5 & 0,653 & Valid \\
\hline
\end{tabular}

Sumber: Data primer yang diolah, 2020

jmm.unram.ac.id 


\section{HASIL PENELITIAN DAN PEMBAHASAN}

\subsection{Uji Hipotesis}

Analisis path dilakukan dengan tujuan mengetahui pengaruh langsung dan pengaruh tidak langsung antara variabel bebas terhadap variabel terikat. Adapun variabel bebas dalam penelitian ini adalah entrepreneurial education. Variabel terikat dalam penelitian ini adalah loyalitas wisatawan. Sedangkan variabel intervening adalah emotional bonding. Adapun hasil pengolahan data dengan menggunakan program spss adalah sebagai berikut:

$$
\begin{gathered}
Z=2,617+0,184 X 1+0,222 X 2+e \\
Y=2,006+0,307 X+0,205 Z+e
\end{gathered}
$$

Langkah pertama dalam analisis jalur adalah membuktikan bahwa ada pengaruh yang signifikan variabel citra destinasi dan tingkat kepuasan terhadap emotional bonding. Hasil analisis untuk mengetahui pengaruh variabel citra destinasi dan tingkat kepuasan terhadap emotional bonding dijelaskan dalam tabel 7 Hasil Analisis Jalur Persamaan Struktual 1.

Tabel 7. Hasil Analisis Jalur Persamaan Struktual 1

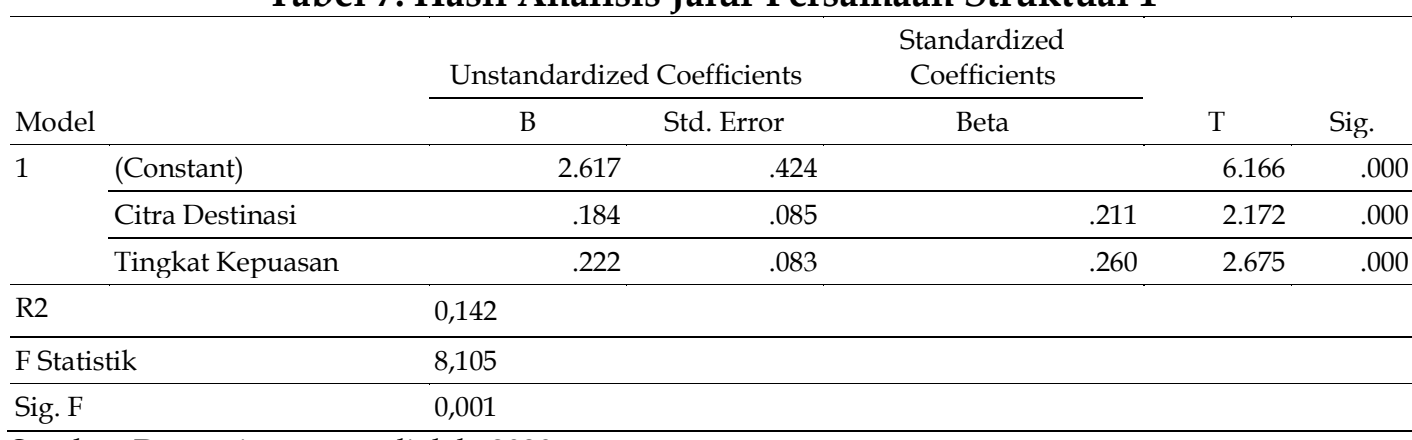

Sumber: Data primer yang diolah, 2020

Nilai error term (e) sebesar 0,142, dimana memiliki emotional bonding yang dipengaruhi oleh citra destinasi dan tingkat kepuasan sebesar 99,86 persen. Oleh karena Standardized Coefficients Beta = 0,211 dan 0,260 dan Sig = 0,000 dan 0,000 $\leq$ 0,05 maka dapat disimpulkan citra destinasi dan tingkat kepuasan berpengaruh positif signifikan terhadap emotional bonding.

Langkah kedua dalam analisis jalur adalah membuktikan bahwa ada pengaruh yang signifikan variabel citra destinasi, tingkat kepuasan dan emotional bonding terhadap variabel loyalitas wisatawan. Hasil analisis untuk mengetahui pengaruh citra destinasi, tingkat kepuasan dan emotional bonding terhadap variabel loyalitas wisatawan dilihat pada tabel 8 Hasil analisis jalur persamaan Struktural 2.

Tabel 8. Hasil Analisis Jalur Persamaan Struktual 2

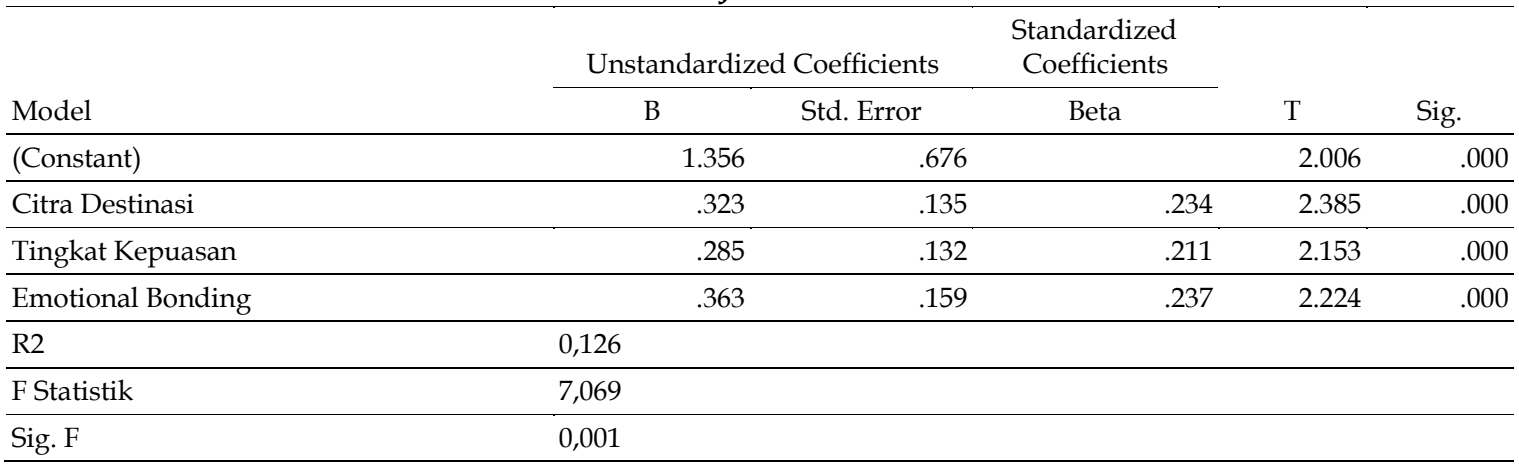

Sumber: Data primer yang diolah, 2020 
Nilai error term (e) sebesar 0,126, dimana memiliki arti Loyalitas Wisatawan yang dipengaruhi oleh Cita Destinasi, Tingkat Kepuasan dan Emotional Bonding sebesar 87,4 persen. Oleh karena Standardized Coefficients Beta 0,234 dan Sigt $=0,000 \leq 0,05$ maka dapat disimpulkan Citra Destinasi berpengaruh positif terhadap Loyalitas Wisatawan. Oleh karena Standardized Coefficients Beta 0,211 dan Sigt $=0,000 \leq 0,05$ maka dapat disimpulkan Tingkat Kepuasan berpengaruh positif terhadap Loyalitas Wisatawan. Oleh karena Standardized Coefficients Beta 0,237 dan Sigt $=0,000 \leq 0,05$ maka dapat disimpulkan Emotional Bonding berpengaruh positif terhadap Loyalitas Wisatawan

Berdasarkan hasil dari koefisien jalur pada hipotesis penelitian, maka dapat digambarkan hubungan kausal antar Citra Destinasi, Tingkat Kepuasan dan Emotional Bonding terhadap variabel Loyalitas Wisatawan. Perhitungan pengaruh variabel antar variabel dirangkum dalam tabel 9 sebagai berikut:

Tabel 9. Pengaruh Langsung dan Pengaruh Tidak Langsung

serta Pengaruh Citra Destinasi, Tingkat kepuasan, Emotional Bonding dan Loyalitas Wisatawan

\begin{tabular}{cccc}
\hline Pengaruh Variabel & $\begin{array}{c}\text { Pengaruh } \\
\text { Langsung }\end{array}$ & $\begin{array}{c}\text { Pengaruh Tidak Langsung } \\
\text { Melalui Emotional Bonding }\end{array}$ & Pengaruh Total \\
\hline X1 terhadap Y & 0,234 & 0,056 & 0,290 \\
\hline X2 terhadap Y & 0,211 & 0,051 & 0,262 \\
\hline Z terhadap Y & 0,237 & - & 0,237
\end{tabular}

Sumber: Data primer yang diolah, 2020

\subsection{Pembahasan}

\subsubsection{Pengaruh Citra Destinasi terhadap Loyalitas Wisatawan}

Pengujian pengaruh citra destinasi terhadap loyalitas wisatawan menunjukkan nilai koefisien sebesar 0,234 dengan tingkat signifikansi sebesar 0,000 < alfa 0,05. Hal ini mengindikasikan adanya pengaruh yang positif dan signifikan citra destinasi terhadap loyalitas wisatawan. Semakin baik citra dari suatu destinasi maka semakin tinggi loyalitas wisatawan terhadap destinasi tersebut.

Hasil penelitian ini sejalan dengan penelitian Citra destinasi memiliki pengaruh positif sebesar 35,2\% terhadap loyalitas konsumen (Weisheng et al, 2016). Penelitian Hern (dalam Monali et al, 2019) juga mengungkapkan bahwa citra destinasi berpengaruh positif dan signifikan terhadap loyalitas wisatawan.

\subsubsection{Pengaruh Tingkat Kepuasan terhadap Loyalitas Wisatawaan}

Pengujian pengaruh tingkat kepuasan terhadap loyalitas wisatawan menunjukkan bahwa Nilai koefisien sebesar 0,211 dengan tingkat signifikansi sebesar 0,000 < a =0,05. Hal ini mengindikasikan adanya pengaruh yang positif dan signifikan variabel tingkat kepuasan terhadap loyalitas wisatawan. Semakin tinggi tingkat kepuasan seseorang maka semakin tinggi pula loyalitas wisatawan terhadap suatu destinasi wisata.

Hasil penelitian ini sejalan dengan penelitian Putri., Farida., dan Dewi, (2015) dalam penelitiannya membuktikan bawa tingkat kepuasan berpengaruh positif dan signifikan terhadap loyalitas wisatawan yang berkunjung ke Candi Borobudur. Selain itu dalam penelitian Ernawati (2012) menyatakan bahwa kepuasan, kepercayaan dan harga sangat kuat mempengaruhi loyalitas wisatawan.Semakin tinggi tingkat kepuasan maka semakin tinggi pula loyalitas wisatawan untuk menggunakan layanan jasa (Wulandari, 2016). 


\subsubsection{Pengaruh Citra Destinasi terhadap Emotional Bonding}

Pengujian pengaruh citra destinasi terhadap emotional bonding menunjukkan nilai koefisien sebesar 0,211 dengan tingkat signifikansi sebesar 0,000 < alfa 0,05. Hal ini mengindikasikan adanya pengaruh yang positif dan signifikan variabel citra destinasi terhadap emotional bonding. Semakin baik citra suatu destinasi maka semakin tinggi ikatan emosional wisatawan pada suatu destinasi wisata.

Hasil penelitian ini mendukung Septiana (2019) dalam penelitiannya menyatakan bahwa kini citra destinasi wisata Malioboro memiliki ikatan emosional bagi wisatawan yang pernah berkunjung di masa lalu.

\subsubsection{Pengaruh Tingkat Kepuasan terhadap Emotional Bonding}

Pengujian pengaruh tingkat kepuasan terhadap emotional bonding menunjukkan nilai koefisien sebesar 0,260 dengan tingkat signifikansi sebesar 0,000 < alfa 0,05. Hal ini mengindikasikan adanya pengaruh yang positif dan signifikan variabel tingkat kepuasan terhadap emotional bonding. Semakin tinggi tingkat kepuasan maka semakin tinggi ikatan emosional wisatawan pada suatu destinasi wisata. Hasil penelitian ini sejalan dengan penelitian Ikatan emosional (emotional bonding) yang kuat terhadap suatu perusahaan ditimbulkan oleh adanya pengaruh dari tingginya tingkat kepuasan dari pelanggan (Putri et al, 2015).

Pengaruh Citra Destinasi dan Tingkat Kepuasan terhadap Loyalitas Wisatawan melalui Emotional Bonding

Dari hasil penelitian diperoleh dengan adanya pengaruh langsung variabel citra destinasi terhadap loyalitas wisatawan sebesar 0,234 sedangkan pengaruh tidak langsung setelah adanya variabel intervening emotional bonding sebesar 0,056 dan pengaruh langsung variable tingkat kepuasan terhadap loyalitas wisatawan sebesar 0,211 dan pengaruh tidak langsung setelah adanya variable intervening emotional bonding sebesar 0,051. Ini menunjukkan bahwa Citra Destinasi dan Tingkat Kepuasan berpengaruh tidak langsung terhadap loyalitas wisatawan melalui emotional bonding sebagai variabel intervening.

Hasil Penelitian ini sejalan dengan penelitian Barnes (2003) mengatakan bahwa pelanggan yang memiliki loyalitas sejati merasakan adanya ikatan emosional yang membuat pelanggan menjadi loyal dan mendorong mereka untuk terus berbisnis dengan organisasi tersebut. Dengan demikian loyalitas konsumen merupakan bukti dari ikatan emosional yang mentransformasikan perilaku pembelian ulang barang atau penggunaan jasa dan adanya kecenderungan niat untuk merekomendasikan kepada orang lain, karena adanya kecintaan atau kedekatan konsumen pada perusahaan penyedia jasa atau organisasi lain (Ernawati, 2011).

\section{KESIMPULAN}

\subsection{Kesimpulan}

Dari hasil penelitian ini didapat beberapa kesimpulan sebagai berikut:

1. Citra Destinasi berpengaruh positif dan signifikan terhadap Loyalitas Wisatawan. Artinya, semakin baik citra dari suatu destinasi maka semakin tinggi loyalitas wisatawan terhadap destinasi tersebut.

2. Tingkat Kepuasan berpengaruh positif dan signifikan terhadap Loyalitas Wisatawan. Artinya, semakin tinggi tingkat kepuasan seseorang maka semakin tinggi pula loyalitas wisatawan terhadap suatu destinasi wisata.

3. Citra Destinasi berpengaruh positif dan signifikan terhadap Emotional Bonding. Artinya, semakin baik citra suatu destinasi maka semakin tinggi ikatan emosional wisatawan pada suatu destinasi wisata. 
4. Tingkat Kepuasan berpengaruh positif dan signifikan terhadap Emotional Bonding. Artinya, emakin tinggi tingkat kepuasan maka semakin tinggi ikatan emosional wisatawan pada suatu destinasi wisata.

5. Variabel emotional bonding memediasi pengaruh citra destinasi dan tingkat kepuasan terhadap loyalitas wisatawan. Bukti empiris menunjukkan bahwa ikatan emosional seseorang terhadap suatu destinasi memediasi hubungan antara cita destinasi dan tingkat kepuasan terhadap loyalitas wisatawan.

\subsection{Saran}

Peneliti berharap dalam penelitian selanjutnya mampu mencakup ruang lingkup yang lebih luas, tidak terbatas oleh responden yang berstatus pilot paralayang yang sudah terdaftar resmi saja melainkan dapat mencakup wisatawan yang datang untuk tandem terbang bersama pilot. Karena penelitian ini hanya mencakup pilot paralayang yang secara resmi terdaftar di FASI NTB.

\section{Acknowledgments}

Penelitian ini ditulis sebagai hasil dari kerjasama antara Kementrian Pemuda dan Olahraga Republik Indonesia dan Universitas Mataram.

\section{DAFTAR PUSTAKA}

Barnes, James.G. 2003. Secrets of Customer Relationship Management. Alih Bahasa: Andreas Winardi, SPd. Yogyakarta: Andi.

Bramson. Robert. 2005. Customer Loyalty 50. Jakarta: Prestasi Pustaka.

Chen, C., dan Tsai, D. 2007. How Destination Image and evaluative factors affect behavioral intentions. Tourism Management

Coban, S. 2012. The effects of the image of destination on tourist satisfaction and loyalty: the case of Cappadocia. European Journal of Social Sciences, 29 (2) : 222-232

Egan, John, 2001, Relationship Marketing, Exploring Relational Strategies in Marketing. Prentice Hall, Hal 3 - 350, Orlando.

Ernawati, N dan Nina Kurniasari. 2011. Pengaruh Kepuasan Pelanggan, Kepercayaan dan Harga terhadap Loyalitas Pelanggan Laundry Kencling Semarang. Jurnal Mahasiswa Q MAN. Vol 1, No.3, 57-68

Ernawati, N dan Nina Kurniasari. 2012. Pengaruh Kepuasan Pelanggan, Kepercayaan dan Harga terhadap Loyalitas Pelanggan Laundry Kencling Semarang. Jurnal Mahasiswa Q MAN. Vol 1, No.3, 57-68

Hanif, A. Kusumawati, A. danMawardi. (2016). Pengaruh Citra Destinasi Terhadap Kepuasan Wisatawan Serta Dampaknya Terhadap Loyalitas Wisatawan (Studi Pada Wisatawan Nusantara Yang Berkunjung Ke Kota Batu). Jurnal administrasi bisnis (JAB) Vol. 38 No. 1.

Ismayanti, 2010. Pengantar Pariwisata, Jakarta PT, Grasindo

Kotler, Philip, 2003, Marketing Management, 11 $1^{\text {th }}$ Edition, New Jersey: Prentice Hall Int'l.

Lee, J., Kyle, G., \& Scott, D. (2012). The Mediating Effect of Place Attachment onthe Relationship between Festival Satisfaction and Loyalty to the Festival Hosting Destination. Journal of Travel Research, 51(6), 754-767.

Ling, L.Q., Karim, M.S., Othman, M., Adzahan, N.M., dan Ramachandran, S. (2010). "Relationship Between Malaysian Food Image, Tourist Satisfaction, and Behavioural Intention". World Applied Sciences Journal (Special Issue of Tourism \& Hospitality), 10(1), pp. 164-171.

Lovelock, Ch., Jochen W., dan Jacky M.2010. Pemasaran Jasa, Manusia, Teknologi, Strategi. Terjemah oleh: Dian Wulandari dan Devri Barnadi Putera. Jilid 2, Edisi Ketujuh. jmm.unram.ac.id 
Jakarta : Erlangga. 2010. Pemasaran Jasa: Manusia, Teknologi, Strategi. Edisi Ketujuh. Diterjemahkan oleh Dian Wulandari dan Devri Barnadi Putera. Jakarta: Erlangga.

Monali, Noval. Hasanuddin Bua. Nursaban Rommy. 2019. Pengaruh Citra Destinasi Terhadap Kepuasan Dan Loyalitas Wisatawan (Effect Of Destination Image On Satisfaction And Tourist Loyalty). JUMBO Vol. 3, No.2, Agustus 2019, hal.01-12. eISSN 2502-4175

Putra, Sang Putu Angga Mahendra. 2017. Pengaruh E-Wom Terhadap Citra Destinasi, Kepuasan dan Loyalitas (Studi Pada Kunjungan Wisata di DIY). MODUS Vol.29 (2): 201-218

Putri, Ratna Acintya, Naili Farida dan Reni Shinta Dewi. 2015. Pengaruh citra destinasi, fasilitas wisata dan experiental marketing terhadap loyalitas melalui kepuasan (studi pada pengunjung domestik taman wisata candi borobudur). Jurnal Ilmu Administrasi Bisnis. Vol 4, No 12015

Septiana, Azizah Dwi. 2018. Pesona Malioboro Sebagai Daya Tarik Wisata Andalan Di Yogyakarta. Domestic Case Study 2018 Sekolah Tinggi Pariwasata Ambarrukmo Yogyakarta

Soegoto, Agus Supandi. 2013. Persepsi Nilai Dan Kepercayaan Terhadap Kepuasan Dan Dampaknya Terhadap Loyalitas Konsumen. Jurnal EMBAVol.1 No.3 September 2013, Hal. 1271-1283. ISSN 2303-1174.

Surya, Elfitra Desy. 2018. Analisis Pemasaran Pariwisata Halal di Propinsi Sumatera Barat. http://repositori.usu.ac.id. Diakses pada tanggal 6 Maret 2020

Tjiptono, Fandy dan Georgeus Chandra. 2007. Service Quality Satisfaction. Yogyakarta: Andi Yogyakarta 